\title{
Single Pill Regimen Leads to Better Adherence and Clinical Outcome in Daily Practice in Patients Suffering from Hypertension and/ or Dyslipidemia: Results of a Meta-Analysis
}

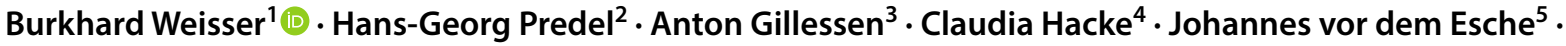 \\ Gerd Rippin $^{6} \cdot$ Andrea Noetel $^{7}$. Olaf Randerath ${ }^{7}$
}

Received: 28 May 2019 / Accepted: 16 March 2020 / Published online: 26 March 2020

(c) The Author(s) 2020

\begin{abstract}
Introduction Cardiovascular diseases (CVD) represent the first cause of mortality in western countries. Hypertension and dyslipidemia are strong risk factors for CVD, and are prevalent either alone or in combination. Although effective substances for the treatment of both factors are available, there is space for optimization of treatment regimens due to poor patient's adherence to medication, which is usually a combination of several substances. Adherence decreases with the number of pills a patient needs to take. A combination of substances in one single-pill (single pill combination, SPC), might increase adherence, and lead to a better clinical outcome.

Aim We conducted a meta-analysis to compare the effect of SPC with that of free-combination treatment (FCT) in patients with either hypertension, dyslipidemia or the combination of both diseases under conditions of daily practice.

Methods Studies were identified by searching in PubMed from November 2014 until February 2015. Search criteria focused on trials in identical hypertension and/or dyslipidemia treatment as FCT therapy or as SPC. Adherence and persistence outcome included proportion-of-days-covered (PDC), medication possession ratio (MPR), time-to treatment gap of 30 and 60 days and no treatment gap of 30 days $(\mathrm{y} / \mathrm{n})$. Clinical outcomes were all cause hospitalisation, hypertension-related hospitalisation, all cause emergency room visits, hypertension-related emergency room visits, outpatient visits, hypertension-related outpatient visits, and number of patients reaching blood pressure goal. Randomized clinical studies were excluded because they usually do not reflect daily practice.

Results 11 out of 1.465 studies met the predefined inclusion criteria. PDC $\geq 80 \%$ showed an odds ratio (OR) of 1.78 (95\% CI: $1.30-2.45 ; \mathrm{p}=0.004)$ after 6 months and an OR of 1.85 (95\% CI: $1.71 ; 2.37 ; \mathrm{p}<0.001)$ after $\geq 12$ months in favour to the SPC. MPR $\geq 80 \%$ after 12 months also was in favour to SPC (OR 2.13; 95\% CI: $1.30 ; 3.47 ; \mathrm{p}=0.003$ ). Persistence was positively affected by SPC after 6, 12, and 18 months. Time to treatment gap of 60 days resulted in a hazard ratio (HR) of 2.03 (95\% CI: 1.77; 2.33, p < 0.001). The use of SPC was associated with a significant improvement in systolic blood pressure reduction, leading to a higher number of patients reaching individual blood pressure goals (FCT vs SPC results in $\mathrm{OR}=0.77 ; 95 \%$ CI: $0.69 ; 0.85, \mathrm{p}<0.001)$. Outpatient visits, emergency room visits and hospitalisations, both overall and hypertension-related were reduced by SPC: all-cause hospitalisation (SPC vs FCT: $15.0 \%$ vs $18.2 \%$, OR 0.79, 95\% CI 0.67; $0.94, \mathrm{p}=0.009$ ), all-cause emergency room visits (SPC vs FCT: $25.7 \%$ vs $31.4 \%$, OR $0.75,95 \%$ CI $0.65 ; 0.87, \mathrm{p}=0.001$ ) and hypertension related emergency room visits (SPC vs FCT: 9.7\% vs $14.1 \%$, OR 0.65, 95\% CI 0.54; 0.80, p < 0.001).

Conclusions SPC improved medication adherence and clinical outcome parameter in patients suffering from hypertension and/or dyslipidemia and led to a better clinical outcome compared to FCT under conditions of daily practice.
\end{abstract}

Keywords Cardiovascular disease $\cdot$ Hypertension · Dyslipidemia $\cdot$ Adherence $\cdot$ Clinical outcome $\cdot$ Single pill combination . Free-combination treatment

Burkhard Weisser

bweisser@email.uni-kiel.de

Extended author information available on the last page of the article 


\section{Introduction}

Cardiovascular diseases (CVD)represent the first cause of mortality in many western countries. In 2015, 76,013 people died due to coronary heart disease, 49,210 from myocardial infarction, and 47,414 from heart failure in Germany [1]. Hypertension and dyslipidemia are strong risk factors associated with CVD and are prevalent either alone or in combination [2]. In Germany, more than half of the adults $\geq 18$ years have elevated cholesterol $>190$ $\mathrm{mg} / \mathrm{dl}$, about $20 \%$ above $240 \mathrm{mg} / \mathrm{dl}$ [3]. 30\% of German women, and $33 \%$ of men are suffering from hypertension. The prevalence is nearly unchanged since 1998 [4]. Although effective antihypertensive agents are available, only half of the medically treated patients reach a blood pressure (BP) of $<140 / 90 \mathrm{mmHg}$ [5].

An explanation for the poor management of both, dyslipidemia, and hypertension, could be the treatment conditions. Multiple antihypertensive agents are required to achieve target BP in most patients [2]. It has also been observed, that initial low-dose treatment with two or three antihypertensive agents is more efficacious than the standard dose of each monotherapy [6]. However, the number of pills might have an influence on medical adherence. Recent data indicate that each increase in the number of antihypertensive medications might lead in addition to around $80 \%$ increase in nonadherence [7]. This will have clinical implications: non-adherence to guideline-recommended therapies regards hypertension and dyslipidemia was associated with a significant higher rate of major cardiovascular events (MACE) [8].

Reduction of pills by combining different substances in one single pill could be a solution to cover these issues. However, it remains unclear whether this will be a model for daily practice.

The objective of this meta-analysis was to compare adherence and clinical outcomes between single pill (SPC) and lose combination (FCT) in daily practice.

\section{Methods}

A literature search of PubMed was undertaken to identify relevant studies. Studies were eligible for investigation if they fulfilled the following inclusion criteria: (1) patients suffering from hypertension, dyslipidemia, or mixed hypertension and dyslipidemia, (2) compared individual drugs exactly, (3) prospective or retrospective cohort studies, (4) included at least one outcome variable that is recommended for the measurement of adherence or persistence by the ISPOR ${ }^{\mathrm{i}}$ or one of the societies of the indications in question or included other relevant clinical outcome/effectiveness parameter, (5) were conducted in a real-world setting, (6) follow-up period of 6 or more months, and (6) were published in English.

Data from controlled clinical trials are not valid to conclude, whether a combination therapy given as a single pill will have advantages compared with the identical substances in several pills, because patients are closely monitored and reminded to take their medication. Therefore, those studies were excluded from the analysis.

Identified publications were cross-checked for doubles and all remaining abstracts read and checked for eligibility first based on title and abstract and second based on full-text review. Publications remaining were categorized according to the criterion whether the comparison was performed as an exact substance comparison or inaccurately as a comparison of overall substance classes.

\subsection{Statistical Methods}

Two parameters of adherence to medication were used. The Medical Possession Rate (MPR) is calculated as the ratio of the number of days a patient has their medicine on hand to the number of days a patient has to take the medication. The Proportion of Days Covered (PDC) calculates the ratio of number of days the patient is covered by all medications in a period to the total number of days in the period. Therefore, PDC is recommended for patients on multiple therapies.

Odds ratios (OR) associated with the use of SPC vs FCT were calculated for the adherence outcomes PDC $\geq 80 \%$, MPR $\geq 80 \%$, and persistence outcome variable no treatment gap of 30 days. Likewise, ORs are given for reaching JNC-VII blood pressure goal and the effectiveness outcomes all-cause emergency room visits, hypertension-related emergency room visits, all-cause hospitalisation, hypertensionrelated outpatient visits, outpatient visits and hypertensionrelated outpatient visits. Hazard ratios (HR) are used for time to 30-days treatment gap and time to 60-days treatment gap. PDC and MPR are analyzed by mean differences. ORs are either already given in the original publication, or calculated by using the numbers of events and the sample size per treatment group. For mean differences, actual means, the sample sizes and the standard deviations (or standard errors) were used. If events had been reported as percentages, results are recalculated into patient numbers to allow the calculation of ORs. In cases in which a transformation of the ORs or HRs was necessary in order to standardize the direction of the effect sizes, this was done by using the transformation $1 / x$. $Z$-values are computed for testing the null hypothesis that the OR or HR is 1.0 or that the mean difference is 0 . The $I^{2}$-statistic is computed to measure heterogeneity of effects. If significant heterogeneity was demonstrated, a random-effects model will be used for analysis. 
All statistical analyses were performed with the statistic software R. Specifically, the R package "meta" with the R function "metagen" was applied for the statistical models (meta-analytical models) assuming a random effects model.

\section{Results}

From 1.465 initial studies, 11 publications where finally included for further consideration (Fig. 1). Studies are presented in Table 1.

The number of patients included in the studies is shown in Table 1 . The non-weighted mean age was slightly higher in the FCT-group with a mean age of $58.3 \pm 6.9$ years in the SPC, and $59.9 \pm 6.3$ years in the FCT-group.

Persistence, measured as time to a treatment gap of 30 or 60 days or as the occurrence of a 30 days treatment gap within the study period, was higher under SPC. Time to treatment gap of 30 days resulted in HR 1.23 (95\% CI: 1.15; $1.33, \mathrm{p}<0.001)$ and time to treatment gap of 60 days in HR 2.03 (95\% CI: 1.77; 2.33; p < 0.001). The endpoint "30 days gap of treatment" resulted in OR 3.51 (95\% CI: 3.06; 4.02; $\mathrm{p}=0.001$ ).

For the adherence variable PDC $\geq 80 \%$, the OR were 1.78 (95\% CI: $1.30 ; 2.45, \mathrm{p}=0.004)$ after 6 months and OR 1.85 (95\% CI: $1.71 ; 2.37, \mathrm{p}<0.001)$ after $\geq 12$ months in favor to SPC (Figs. 2, 3).

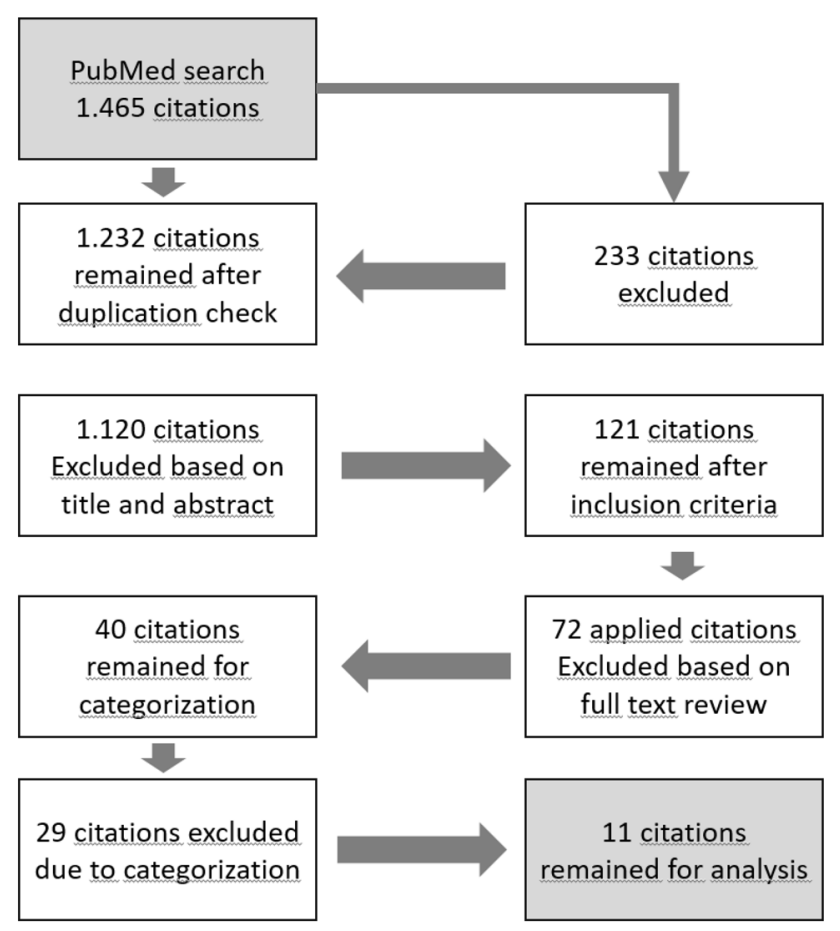

Fig. 1 Flowchart of study selection process
MPR after 12 months was significantly higher for the SPC formulations (OR 2.13; 95\% CI: 1.30; 3.47, $\mathrm{p}<0.0025$ ). Difference in mean MPR at 12 months was also higher for SPC (MD 0.08, 95\% CI: 0.03; 0.13, p=0.0017).

The clinical outcome as measured by reaching individual blood pressure goals was found to be OR 1.22; 95\% CI: $1.10-1.35, \mathrm{p}<0.001$ for one publication.

While there was only a slight reduction in all-cause outpatient visits for SPC (SPC: vs FCT: $97.6 \%$ vs $97.9 \%$, OR $0.89,95 \%$ CI: $0.58-1.36, p=0.58$ ) and HTN-specific outpatient visits (SPC: vs FCT: $82.3 \%$ vs $82.4 \%$, OR $=1.00,95 \%$ CI $0.84-1.18, \mathrm{p}=0.97)$, HTN-specific hospitalization was about the same (SPC vs FCT: $0.7 \%$ vs $0.6, \mathrm{OR}=1.18,95 \%$ CI $0.91-1.53, \mathrm{p}=0.21$ ). Significant advantages for SPC were seen in the clinical outcomes all-cause hospitalisation (SPC vs FCT: $15.0 \%$ vs $18.2 \%$, OR 0.79; 95\% CI: 0.67-0.94, $\mathrm{p}=0.009$ ), all-cause emergency room visits (SPC vs FCT: $25.7 \%$ vs $31.4 \%$, OR 0.75 ; $95 \%$ CI: $0.65-0.87, p=0.0001$ ) and hypertension related emergency room visits (SPC vs FCT: $9.7 \%$ vs $14.1 \%$, OR 0.65 ; 95\% CI: $0.54-0.80$, p < $0.001)$.

\section{Discussion}

The results of our meta-analysis indicate that combining several agents for CVD treatment in one single pill could be an effective solution to reach treatment targets under conditions of daily practice. The main findings of this study were that a single pill combination was beneficial with regard to adherence, persistence, and clinical outcomes.

Clinical data indicate that initial combination therapy is beneficial in the treatment of arterial hypertension [20,21]. Wald et al. conducted a meta-analysis of 42 clinical trials involving almost 11,000 patients. They found that combining any two drugs decreased blood pressure approximately 5 times greater than doubling the standard dose of one drug. The reduction in blood pressure with combined drugs was approximately 5 times greater than doubling the dose of one drug [6, 22]. In a recent study [23], blood pressure control with a fixed-dose triple combination therapy was superior to the free combination of the three drugs (perindopril/indapamide/amlodipine). Combination therapy seems to be mandatory to reach target blood pressure; the average number of drugs required to reach blood pressure goals amounted to more than 3 in trials focusing on cardiovascular morbidity and mortality [24]. However, low adherence to medication is a hurdle to reach these goals in daily practice, especially when patients suffer from comorbidities and intake of additional drugs is required. Chowdhury et al. performed a systematic review and meta-analysis of prospective epidemiological studies in 1,978,919 non-overlapping participants, with 135,627 CVD events and 94,126 cases of all-cause 
Table 1 Eligible studies for meta-analysis

\begin{tabular}{|c|c|c|c|c|c|c|c|}
\hline Study & Indication & $\begin{array}{l}\text { No. of participants } \\
\text { (SPC) }\end{array}$ & $\begin{array}{l}\text { Age in years, mean } \\
(\mathrm{SPC} / \mathrm{FCT})\end{array}$ & $\begin{array}{l}\text { Gender, } \% \text { female } \\
\text { (SPC/FCT) }\end{array}$ & Compounds & Class & $\begin{array}{l}\text { Dose of } \\
\text { medica- } \\
\text { tion }\end{array}$ \\
\hline \multicolumn{8}{|c|}{ Combination with statins } \\
\hline $\begin{array}{l}\text { Hussein et al. } \\
\text { (2010) [9] }\end{array}$ & Hyp/Dys & $35430(3136)$ & $\begin{array}{l}50.0-55.2 / 54.4- \\
56.9^{\mathrm{a}}\end{array}$ & $\begin{array}{l}34.4-44.0 / 41.0- \\
54.6^{\mathrm{a}}\end{array}$ & AML/ATOR & $\mathrm{CCB} /$ Statin & NA \\
\hline $\begin{array}{l}\text { Patel et al. (2008) } \\
\text { [10] }\end{array}$ & Hyp/Dys & $4703(795)$ & $61.4 / 62.1-64.4^{\mathrm{a}}$ & $42.5 / 47.8-57.5^{\mathrm{b}}$ & AML/ATOR & $\mathrm{CCB} /$ Statin & NA \\
\hline $\begin{array}{l}\text { Simons et al. } \\
\text { (2011) [11] }\end{array}$ & Hyp/Dys & $10350(4146)$ & $70.7 / 71.2$ & $54.0 / 54.0$ & AML/ATOR & $\mathrm{CCB} /$ Statin & NA \\
\hline $\begin{array}{l}\text { Balu et al. (2009) } \\
\text { [12] }\end{array}$ & Dys & $\begin{array}{l}8988(6638) \\
\text { MPR }\end{array}$ & $51.9 / 56.0-56.1^{\mathrm{a}}$ & $26.9 / 77.7-83.0$ & Niacin/Lovastatin & Niacin/Statin & NA \\
\hline $\begin{array}{l}\text { Kamat et al (2011) } \\
\text { [13] }\end{array}$ & Dys & $42460(38847)$ & $56.4 / 54.8$ & $44.8 / 37.7$ & $\begin{array}{l}\text { (Niacin or } \\
\text { Ezetimibe)/Sim- } \\
\text { vastatin } \\
\text { Niacin/Lovastatin }\end{array}$ & $\begin{array}{l}\text { (Niacin or } \\
\text { Ezetimibe)/ } \\
\text { Statin }\end{array}$ & NA \\
\hline \multicolumn{8}{|c|}{ Combination without statins } \\
\hline $\begin{array}{l}\text { Ram et al. (2012) } \\
\text { [14] }\end{array}$ & Нyp & $46706(32807)$ & $\begin{array}{l}\text { Only numbers per } \\
\text { age range are } \\
\text { given }\end{array}$ & $\begin{array}{l}64.4-65.9 / 59.5- \\
63.5\end{array}$ & $\begin{array}{l}\text { AML/OLM (\& } \\
\text { AML/VAL) }\end{array}$ & $\mathrm{CCB} / \mathrm{ARB}$ & NA \\
\hline $\begin{array}{l}\text { Levi et al. (2016) } \\
\text { [15] }\end{array}$ & Hyp & $4890(3057)$ & $66.6 / 68.1$ & $52.2 / 50.8$ & AML/OLM & $\mathrm{CCB} / \mathrm{ARB}$ & NA \\
\hline $\begin{array}{l}\text { Brixner et al. } \\
\text { (2008) [16] }\end{array}$ & Нyp & $2189(1628)$ & $\begin{array}{l}\text { Only numbers per } \\
\text { age range are } \\
\text { given }\end{array}$ & $49 / 41.5$ & VAL/HCTZ & ARB/HCTZ & NA \\
\hline $\begin{array}{l}\text { Machnicki et al. } \\
\text { (2015) [17] }\end{array}$ & Hyp & $3768(1884)$ & $48.4 / 48.0$ & $66.4 / 66.8$ & AML/VAL/HCTZ & $\mathrm{CCB} / \mathrm{ARB} / \mathrm{HCTZ}$ & NA \\
\hline $\begin{array}{l}\text { Jackson et al. } \\
\text { (2008) [18] }\end{array}$ & Нyр & 908 (619) & $\begin{array}{l}\text { Only numbers per } \\
\text { age range are } \\
\text { given }\end{array}$ & $57.6-58.5 / 55.4$ & AML/VAL/HCTZ & CCB/ARB/HCTZ & NA \\
\hline $\begin{array}{l}\text { Xie et al. (2014) } \\
\text { [19] }\end{array}$ & Hyp & $17465(8516)$ & $54.8 / 59.1-63.9^{\mathrm{a}}$ & $45.2 / 49.5-51.3$ & $\begin{array}{l}\text { AML/(VAL or } \\
\text { OLM)/HCTZ }\end{array}$ & $\mathrm{CCB} / \mathrm{ARB} / \mathrm{HCTZ}$ & NA \\
\hline
\end{tabular}

$S P C$ single pill combination, $F C T$ free-combination treatment, $H y p$ hypertension, $D y s$ dyslipidemia, $A M L$ amlodipine, $A T O R$ atorvastatin, VAL valsartan, $O L M$ olmesartan, $H C T Z$ hydrochlorothiazide, $C C B$ calcium channel blocker, $A R B$ angiotensin receptor blocker, $N A$ not applicable

${ }^{a}$ The study population was stratified into different cohorts and/or patient characteristics are given based on the use of CCB and/or statin therapies

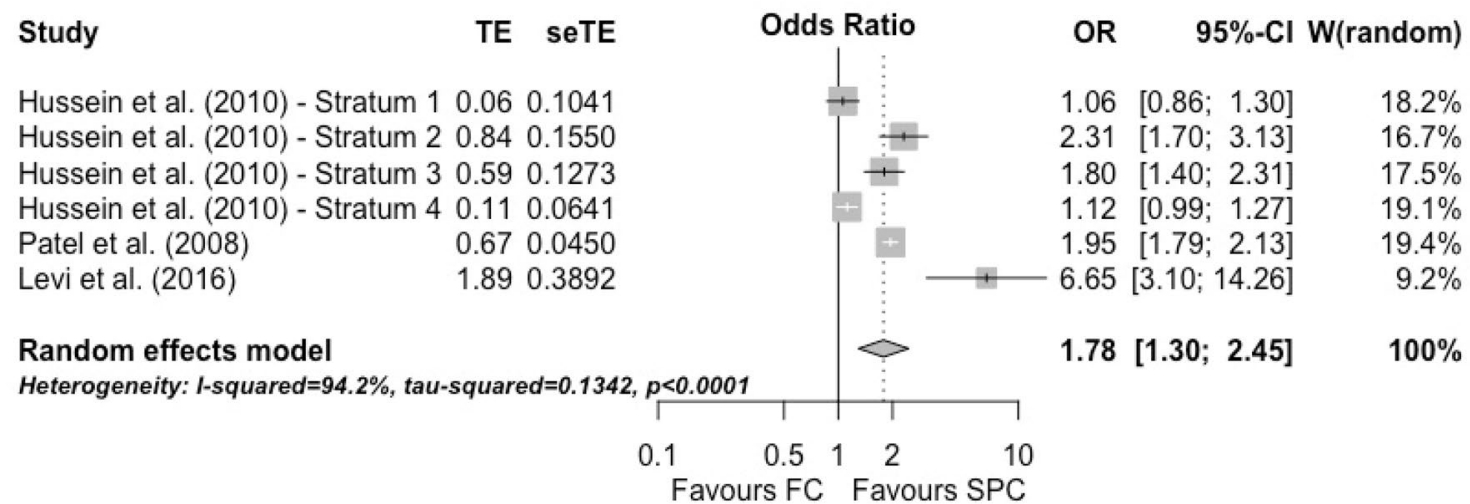

Fig. 2 Proportion-of-days-covered (PDC) $\geq 80 \%$ after 6 months 


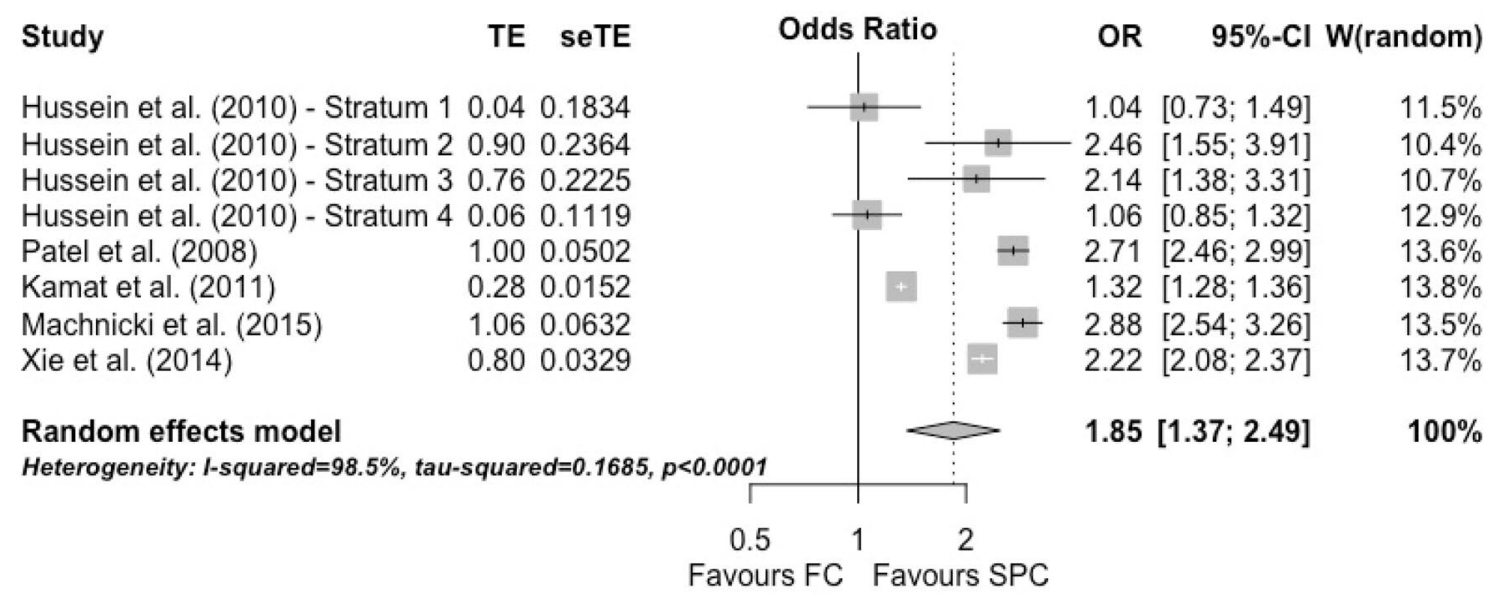

Fig. 3 Proportion-of-days-covered (PDC) $\geq 80 \%$ after $\geq 12$ months

mortality. They found a poor adherence to CVD medication in $40 \%$ of patients and concluded, that a considerable proportion of all CVD events ( $~ 9 \%$ in Europe) could be attributed to poor adherence to vascular medications alone, and that the enhancement of adherence could help to maximize the potentials of effective cardiac therapies in the clinical setting [25].

In the present study, clinical trials were excluded from the analysis as patients are forced to be more compliant compared to everyday life. In an interventional study, less or no difference in compliance can be deduced due to the specific design of the study. Focusing on data from real world settings is more important because the differences between FCT and SPC therapy arise from the way medications are used, and patterns of medication used in clinical trials may not be generalizable. Andrade et al. compared the rates of drug discontinuation in primary care settings with the rates reported in clinical trials. The risks of discontinuation were substantially higher in the primary care settings than in randomized clinical trials [26].

To minimize bias, a rigorous selection of available studies has been performed. Selected studies needed to perform an exact substance comparison. Additionally, only outcomes that were clearly marked as adjusted for baseline conditions and confounders (e.g. by matching) were considered eligible. Among patients receiving antihypertensives or a combination of antihypertensive and cholesterol-lowering therapy, single pill treatment was associated with a significantly better adherence and better clinical outcomes compared with the identical lose substance combination under conditions of daily practice.

A clear benefit of SPC treatment strategy was seen on adherence, persistence, and clinical outcomes. First, there was evidence for a significant benefit of SPC over FCT on medication adherence measured either as $\mathrm{PDC} \geq 80 \%$, MPR $\geq 80 \%$ or mean PDC or MPR values. Differences between both treatment strategies could be demonstrated at 3 months, 6 months and $\geq 12$ months. In most of the studies, the effect sizes were more evident after 12 months compared to 3 or 6 months, which is consistent with the common reasoning that an advantage of single pill combinations over LP_-if existent-should increase over time. A limitation might be that we could not identify studies following our inclusion criteria with an observation period of more than 12 months. However, poor adherence already seems to be an issue immediately after initiation of CVD treatment. Chapman et al. conducted a retrospective cohort study in 8,406 enrollees in managed care who planned treatment with antihypertensive (AH) and lipid-lowering (LL) drugs. They measured adherence as PDC in 3-months intervals following initiation of concomitant therapy (mean follow-up, 12.9 months). Patients were considered adherent if they had filled prescriptions sufficient to cover at least $80 \%$ of days with both classes of medication. They found only 1 in 3 patients adherent to both medications after 6 months [27].

Heterogeneity between trials for each outcome was high and a major limitation of the study. We considered the different methods to determine persistence, analysed time points and specific basal characteristics for each trial as the most likely causes of this heterogeneity. However, each study showed superiority of SPC treatment regarding persistence. This was independent from the methods used or the time points investigated. Overall, both adherence and persistence were consistently higher for SPs.

We also investigated whether high adherence and persistence will result into better clinical outcomes. Ram et al. demonstrate a significant benefit of combination therapy with respect to the main goal of reaching the blood pressure target recommended by international guidelines [14]. This was supported by additional analyses regarding the mean change 
of systolic and diastolic blood pressure. Similarly, Kumagai et al. enrolled 196 patients with hypertension already being treated with FCT of angiotensin-II receptor blockers (ARB) and amlodipine. The FCT of ARB and amlodipine were replaced with the same dose of the SPC combinations. The average home measured blood pressure in all patients receiving SPC was significantly lower than those receiving FCT accompanied with increasing drug adherence [28].

With respect to clinical outcomes, Machnicki et al. showed a significant advantage of SPC treatment regarding hospitalizations, emergency room visits and hypertensionrelated emergency room visits. Thus, the positive effects on adherence and persistence were seen to be translated into clinical outcome and effectiveness parameters as well [17]. These findings are supported by a recent published study by Verma et al. [28]. They conducted a population-based retrospective cohort study of 13,350 individuals with up to 5 years of follow-up. Patients received an angiotensin-converting enzyme inhibitor (ACEI) or angiotensin II-receptor blocker (ARB) plus one thiazide diuretic. The authors conducted 2 analyses to examine the association between adherence and patient outcomes. First, they performed an ontreatment analysis to determine whether outcomes differed between groups while patients were on treatment. Second, they conducted an intention-to-treat analysis that followed individuals allowing for breaks in treatment to quantify the difference in drug adherence between groups and assessed its impact on clinical outcomes. They did not observe a significant difference in the primary outcome between groups in the on-treatment analysis. However, in the intention-totreat analysis, the proportion of total follow-up days covered with medications was significantly higher in the SPC group than in the FCT, and the primary outcome was less frequent in SPC recipients [28]. This study prescribes a simple, but important rationale: 1. SPC improved medication intake 2. Improved medication intake enhances prognosis, 3. SPC improves prognosis.

The strict inclusion criteria of our study lead to a few limitations. Only four studies used ICD-codes for the identification of patients' eligibility. All other studies identified eligible patients by prescription data only. This might lead to an additional variance as lipid lowering and antihypertensive drugs can be prescribed in various indications and for various reasons. Lipid lowering drugs can be prescribed in hypercholesterinaemia, in conditions of primary, secondary, and tertiary prevention; antihypertensive drugs in hypertension, coronary heart disease or heart failure. However, data gathered in this analysis have originally been adjusted for baseline characteristics and confounders and rigid criteria for study inclusion were applied to ensure correct statistical adjustment (e.g. matching). Although many studies could be identified that investigate the effects on adherence and persistence, it is a limitation that only a few studies were found to provide comparable outcome data for clinical outcomes and effectiveness. Unfortunately, it was not possible to do any subgroup analyses for men and women in order to consider differences in medication adherence due to a lack of data specific to gender.

Our analysis does not provide any safety data. Thus, any information about potential harmful effects of a SPC or FCT approach are missing. This should be considered by the planning of future studies.

"Drugs don't work in patients, that do not take them". This famous statement from C. Everett Koop, MD, an US General Surgeon given in 1985 sounds simple. However, the transfer of the reverse conclusion into daily practice does not seem to be that easy. The results of our analysis suggest that an SPC regimen could support patients to take their drugs which might easily to be implemented into daily practice. Certainly, the present meta-analysis gathered an important amount of information, but, at the same time, relevant limitations must be considered and a careful approach should be demanded to avoid misleading conclusions.

\section{Conclusions}

SPC improved medication adherence, persistence and clinical outcome parameter in patients suffering from hypertension and/or dyslipidemia compared to FCT under conditions of daily practice. The data of our analysis suggest that SPC could be a tool to maximize the potentials of effective cardiac therapies in the clinical setting.

Acknowledgements Open Access funding provided by Projekt DEAL.

\section{Compliance with Ethical Standards}

Conflict of interest A Noetel and O. Randerath are employees of APONTIS PHARMA GmbH \& Co. KG. J. vor dem Esche and G. Rippin have received research grants from APONTIS PHARMA GmbH \& Co. KG. HG. Predel and B. Weisser received a speaker honorarium from APONTIS PHARMA GmbH \& Co. KG. C. Hacke and A. Gillessen declare that they have no conflict of interest.

Research involving human participants and/or animals Not applicable.

Informed consent Not applicable.

Open Access This article is licensed under a Creative Commons Attribution-NonCommercial 4.0 International License, which permits any non-commercial use, sharing, adaptation, distribution and reproduction in any medium or format, as long as you give appropriate credit to the original author(s) and the source, provide a link to the Creative Commons licence, and indicate if changes were made. The images or other third party material in this article are included in the article's Creative Commons licence, unless indicated otherwise in a credit line to the material. If material is not included in the article's Creative Commons licence and your intended use is not permitted by statutory regulation or exceeds the permitted use, you will need to obtain permission 
directly from the copyright holder.To view a copy of this licence, visit http://creativecommons.org/licenses/by-nc/4.0/.

\section{References}

1. Destatis.de [homepage on the internet]. Wiesbaden: statistisches bundesamt gesundheit. Todesursachen in Deutschland 2015. Fachserie b12: 2017. http://www.Destatis.de. Accessed 18 Jul 2018.

2. Kostis JB. The importance of managing hypertension and dyslipidemia decrease cardiovascular disease. Cardiovasc Drugs Ther. 2007;21:297-309.

3. Rki.de [homepage on the internet]. Berlin: Robert Koch Institut. Faktenblatt zu GEDA 2012: Ergebnisse der Studie »Gesundheit in Deutschland aktuell 2012«, Fettstoffwechselstörungen: 2017. http://www.rki.de. Accessed 18 Jul 2018.

4. Neuhauser H, Thamm M, Ellert U. Blutdruck in Deutschland 2008-2011. Bundesgesundheitsbl. 2013;56:795-801.

5. Rki.de. [homepage on the internet]. Berlin: Robert Koch Institut. Der Blutdruck in Deutschland ist gesunken, das Präventionspotential bleibt aber hoch. Epidemiologisches Bulletin 5/201533-40 2017. http://www.rki.de. Accessed 18 Jul 2018.

6. Wald DS, Law M, Morris JK, Bestwick JP, Wald NJ. Combination therapy versus monotherapy in reducing blood pressure: meta-analysis on 11,000 participants from 42 trials. AM J Med. 2009;122(3):290-300.

7. Gupta P, Patel P, Strauch B, Lai FY, Akbarov A, Marešová V, et al. Risk factors for nonadherence to antihypertensive treatment. Hypertension. 2017;69:1-8.

8. Bansilal S, Castellano JM, Garrido E, Wei HG, Freeman A, Spettell C, et al. Assessing the impact of medication adherence on long-term cardiovascular outcomes. J Am Coll Cardiol. 2016;68:789-801.

9. Hussein MA, Chapman RH, Benner JS, Tang SSK, Salomon HA, Joyce A, et al. Does a single-pill antihypertensive/lipid-lowering regimen improve adherence in US managed care enrolees? A nonrandomized, observational, retrospective study. Am J Cardiovasc Drugs. 2010;10(3):193-202.

10. Patel BV, Leslie RS, Thiebaud P, Nichol MB, Tank SSK, Solomon $\mathrm{H}$, et al. Adherence with single-pill amlodipine/atorvastatin vs a two-pill regimen. Vasc Health Risk Manag. 2008;4(3):673-81.

11. Simons LA, Ortiz M, Calcino G. Persistence with a single pill versus two pills of amlodipine and atorvastatin: the Australian experience, 2006-2010. MJA. 2011;195(3):135-7.

12. Balu S, Simko RJ, Quimbo RM, Cziraky JM. Impact of fixed-dose and multi-pill combination dyslipidemia therapies on medication adherence and the economic burden of sub-optimal adherence. Curr Med Res Opin. 2009;25(11):2765-75.

13. Kamat SA, Bullano MF, Chang CL, Ghandi SK, Cziraky MJ. Adherence to single-pill combination versus multiple-pill combination lipid-modifying therapy among patients with mixed dyslipidemia in a managed care population. CMRO. 2011;27(5):961-8.

14. Ram CV, Vasey J, Panjabi S, Qian C, Quah R. Comparative effectiveness analysis of amlodipine/renin-angiotensin system blocker combinations. J Clin Hypertens (Greenwich). 2012;14(9):601-10.
15. Levi M, Pasqua A, Cricelli I, Cricelli L, Piccini P, Parretti D, et al. Patient adherence to olmesartan/amlodipine combinations: fixed versus extemporaneous combinations. J of Manag Care Spec Pharm. 2016;22(3):255-62.

16. Brixner DI, Jackson KC II, Sheng X, Nelson R, Keskinasián A. Assessment of adherence, persistence, and costs among valsartan and hydrochlorothiazide retrospective cohorts in free-and fixeddose combinations. Curr Med Res Opin. 2008;24:2597-607.

17. Machnicki G, Ong SH, Chen W, Wei ZJ, Kahler KH. Comparison of amlodipine/valsartan/hydrochlorothiazide single pill combination and free combination: adherence, persistence, healthcare utilization and costs. Curr Med Res Opin. 2015;31(12):2287-96.

18. Jackson KC II, Sheng X, Nelson RE, Keskinasian A, Brixner DI. Adherence with multiple-combination antihypertensive pharmacotherapies in a US managed care database. Clin Ther. 2008;30(8):1558-63.

19. Xie L, Frech-Tamas F, Marrett E, Baser O. A medication adherence and persistence comparison of hypertensive patients treated with single-, double- and triple-pill combination therapy. Curr Med Res Opin. 2014;30(12):2415-22.

20. Degli Esposti L, Saragoni S, Buda S, Degli Esposti EL. Drug adherence to olmesartan/amlodipine fixed combination in an Italian clinical practice setting. Clin Econ Outcomes Res. 2014;6:209-16.

21. Dezii CM. A retrospective study of persistence with single-pill combination therapy vs concurrent two-pill therapy in patients with hypertension. Manag Care. 2001;2:6-10.

22. Canbekan B. Rational approaches to the treatment of hypertension: drug therapy-monotherapy, combination, or fixed-dose combination? Kidney Int Suppl. 2013;3:349-51.

23. Mazza A, Lenti S, Schiavon L, Sacco AP, Dell'Avvocata F, Rigatelli G, Ramazzina E. Fixed-dose triple combination of antihypertensive drugs improves blood pressure control: from clinical trials to clinical practice. Adv Ther. 2017;34(4):975-85.

24. Chowdhury R, Khan H, Heydon E, Shroufi A, Fahimi S, Moore $\mathrm{C}$, et al. Adherence to cardiovascular therapy: a metaanalysis of prevalence and clinical consequences. Eur Heart J. 2013;34(38):2940-8.

25. Andrade SE, Walker AM, Gottlieb LK, Hollenberg NK, Testa MA, Saperia GM, et al. Discontinuation of antihyperlipidemic drugs-do rates reported in clinical trials reflect rates in primary care settings? N Engl J Med. 1995;332(17):1125-31.

26. Chapman RH, Benner JS, Petrilla AA, Tierce JC, Collins SR, Battleman DS, et al. Predictors of adherence with antihypertensive and lipid-lowering therapy. Arch Intern Med. 2005;165(10):1147-52.

27. Kumagai N, Onishi K, Hoshino K, Nakamori S, Kitai T, Yazu $\mathrm{T}$, et al. Improving drug adherence using fixed combinations caused beneficial treatment outcomes and decreased healthcare costs in patients with hypertension. Clin Exp Hypertens. 2013;35(5):355-60.

28. Verma AA, Khuu W, Tadrous M, Gomes T, Mamdani MM. Fixeddose combination antihypertensive medications, adherence, and clinical outcomes: a population-based retrospective cohort study. PLoS Med. 2018;15(6). http://journals.plos.org/plosmedicine/artic le?id=10.1371/journal.pmed.1002584. 


\section{Affiliations}

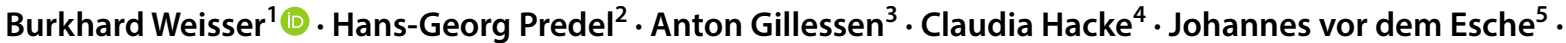 Gerd Rippin $^{6} \cdot$ Andrea Noetel $^{7} \cdot$ Olaf Randerath $^{7}$}

\author{
Hans-Georg Predel \\ predel@dshs-koeln.de \\ Anton Gillessen \\ Anton.Gillessen@hjk-muenster.de \\ Claudia Hacke \\ claudia.hacke@uksh.de \\ Johannes vor dem Esche \\ j.vordemEsche@Codiplan.de \\ Gerd Rippin \\ Gerd.Rippin@quintiles.com \\ Andrea Noetel \\ Andrea.Noetel@ apontis-pharma.de \\ Olaf Randerath \\ Olaf.Randerath@apontis-pharma.de
}

1 Institut für Sportwissenschaft, Christian-AlbrechtsUniversität zu Kiel, Olshausenstraße 74, 24098 Kiel, Germany

2 Instituts für Kreislaufforschung und Sportmedizin, Deutsche Sporthochschule Köln, Cologne, Germany

3 Herz-Jesu Krankenhaus Münster-Hiltrup, Münster, Germany

4 Klinik für Kinder- und Jugendmedizin I, Universitätsklinikum Schleswig-Holstein, Campus Kiel, Kiel, Germany

5 CODIPLAN Gesellschaft für Concept, Dialog und Planung GmbH, Bergisch Gladbach, Germany

6 IQVIA, Neu-Isenburg, Germany

7 APONTIS Pharma GmbH \& Co. KG, Monheim am Rhein, Germany 